\title{
Perception of musical tension in short chord sequences: The influence of harmonic function, sensory dissonance, horizontal motion, and musical training
}

\author{
EMMANUEL BIGAND \\ LEAD-CNRS, Université de Bourgogne, Dijon, France \\ RICHARD PARNCUTT \\ McGill University, Montreal, Quebec, Canada \\ and \\ FRED LERDAHL \\ Columbia University, New York, New York
}

\begin{abstract}
This study investigates the effect of four variables (tonal hierarchies, sensory chordal consonance, horizontal motion, and musical training) on perceived musical tension. Participants were asked to evaluate the tension created by a chord $\mathrm{X}$ in sequences of three chords $\{\mathrm{C}$ major $\rightarrow \mathrm{X} \rightarrow \mathrm{C}$ major $\}$ in a $\mathrm{C}$ major context key. The $\mathrm{X}$ chords could be major or minor triads major-minor seventh, or minor seventh chords built on the 12 notes of the chromatic scale. The data were compared with Krumhansl's (1990) harmonic hierarchy and with predictions of Lerdahl's (1988) cognitive theory, Hutchinson and Knopoff's (1978) and Parncutt's (1989) sensory-psychoacoustical theories, and the model of horizontal motion defined in the paper. As a main outcome, it appears that judgments of tension arose from a convergence of several cognitive and psychoacoustics influences, whose relative importance varies, depending on musical training.
\end{abstract}

Music and spoken language are complex auditory sequences of events that evolve through time. In both, it is striking that listeners usually perceive events as progressing in a coherent, dynamic way. In spoken language, this temporal coherence is due to semantics and to syntactic and contextual information; it also results from the fact that language usually refers to a well-identified external reality.

Such information has no clear equivalent in music (Clarke, 1989). In contrast, a number of music theorists have considered that intuition of coherent progression through time is mainly determined by the tension-relaxation relations that exist among musical events (Lerdahl \& Jackendoff, 1983; Meyer, 1956; Schenker, 1935). In the Western tonal system, these tension-relaxation relations are for one part determined by the harmonic relations that exist among chords. Chord designates the simultaneous sounding of three or more notes. In the present study, all chords contained four notes. Following standard usage, we refer to them as soprano, tenor, alto, and bass voices. It has been

We would like to thank F. Madurell for assisting the experimentation and the anonymous reviewers for their insightful comments, which greatly improved the manuscript. R.P. is with the Faculty of Music at McGill; F.L. is in the Department of Music at Columbia. Correspondence concerning this article should be addressed to $E$. Bigand, LEAD, Université de Bourgogne, Faculté des Sciences, 6 Bd. Gabriel, F-21000 Dijon. France (e-mail: bigand@satie.u-bourgogne.fr). argued that some chords instill in a given context a strong musical tension that is relaxed, or resolved, by more stable chords (Lerdahl \& Jackendoff, 1983; Meyer, 1956, 1973). For example, in the key of $\mathrm{C}$ major, the chord containing the notes G-B-D-F (dominant seventh chord) creates tension partly because of the tritone relation between the tones $B$ (leading tone) and $F$ (the seventh of the chord). This tension needs to be resolved to the tones $\mathrm{C}$ and $\mathrm{E}$, respectively, of the $\mathrm{C}$ major triad (tonic chord). The succession of these two chords creates an authentic cadence that has a strong conclusive character. Tension-relaxation relations are so structurally important that often the relaxation can be delayed in time. A simple case occurs at the end of a concerto movement, when the soloist improvises a long sequence that is largely based on the dominant chord, whose tension is finally resolved by the entrance of the orchestra.

According to Schenker's (1935) theory, tonal musical pieces may be analyzed as recursive elaborations of a fundamental tensing-relaxing relation defined by the tonicdominant-tonic chords. Each level of this elaboration displays more local tensions, which have strong implications about the (more relaxing) events to occur in the piece. Because listeners are assumed to expect musical relaxations, tension-relaxation relations are considered by several music theorists and psychologists as the "glue" that links musical events in the entire time span of the piece (Francès, 1958; Imberty, 1979; Lerdahl \& Jackendoff, 1983). 
Musical tension and musical expectancies are ipso facto quite related phenomena. During the past decade, it has been shown that musical expectancy is governed by several factors, including melodic interval size (Carlsen, 1981; Unyk \& Carlsen, 1987), melodic contour (Boltz \& Jones, 1986), rhythmic features (Boltz, 1993; Jones, 1987; Jones, Boltz, \& Kidd, 1982; Jones, Boltz, \& Klein, 1993; Schmuckler, 1990), and tonal and harmonic structures (Abe \& Oshino, 1990; Bharucha \& Stoeckig, 1986, 1987; Schmuckler, 1989; Schmuckler \& Boltz, 1994). Musical tension and relaxation, created by chords, appears to be linked to the musical expectancies governed by harmonic structures. A chord that instills musical tension generates the expectancy that a more relaxing chord will resolve this tension. In turn, a chord that realizes (or confirms) such expectation creates a musical relaxation. In short chord sequences, musical tension and musical expectancy may be viewed as two co-occurring phenomena. Therefore, we may assume that studying either should provide a complementary insight about similar or related aspects of music cognition.

In music theory, musical tension is explained by several variables: the tonal function (see below) of the chords inside a musical context (Costère, 1954; Koechlin, 1930; Riemann, 1893; Schenker, 1935), their acoustical or sensory consonance (Helmholtz, 1877; Rameau, 1722), and the kind of melodic organization (referred to henceforth as horizontal motion) that exists between the four voices (Ansermet, 1961). Many authors underline the necessity of distinguishing these factors (Koechlin, 1930; Chailley, 1951). Indeed, a chord can be very dissonant, while having a stable tonal function-as, for example, the minor chord with a major seventh that ends some jazz pieces. Conversely, a consonant chord can have an unstable tonal function - as, for example, a modulating dominant chord.

Psychological approaches to musical tension differ in the factors that they emphasize: cognitive approaches emphasize the importance of tonal function (Bharucha, 1984; Bigand, 1990, 1993b; Krumhansl, 1990; Lerdahl, 1988; Lerdahl \& Jackendoff, 1983), and more perceptual theories underline the psychoacoustical features of chords (Helmholtz, 1877; Mathews, Pierce, \& Roberts, 1987; Parncutt, 1989; Roberts \& Shaw, 1984). There is no account of the effect of horizontal motion in chord progressions in psychological theory, despite the important role played by melodic contour in music perception (see Dowling \& Harwood, 1986, for a review).

The main purpose of this study was to investigate the effects of musical function, sensory consonance, and horizontal motion on perceived musical tension in a short chord sequence, played with piano-like sounds. The data were compared with Krumhansl's (1990) harmonic hierarchy values, with Lerdahl's (1988) tonal pitch space distances, with sensory dissonance as formulated by Hutchinson and Knopoff (1978), and with pitch commonality as formulated by Parncutt (1989). Let us consider each approach in some detail.

\section{The Cognitive Approach to Musical Tension}

Lerdahl's (1988) and Krumhansl's (1990) theories are cognitive, in that listeners are assumed to possess implicit knowledge of tonal hierarchies. While listening to music, they might use this knowledge to confer a specific musical tension or relaxation to the events, depending on their place in the tonal hierarchy.

Tonal harmonic hierarchies and musical tension. The tonal harmonic hierarchy refers to a set of principles specific to the Western musical system. From a set of 12 notes (the chromatic scale), recycled identically at each octave, several subsets of seven notes, called diatonic scales, are defined. For each scale, seven diatonic triads are possible, each on a different degree of the scale. The notes of a diatonic triad all belong to the prevailing diatonic scale ( $\mathrm{C}$ major scale in the present paper). In Western music, a triad is a simultaneity of three tones, usually called the root, third, and fifth. Note that if one or more of these is doubled (i.e., played in more than one octave register), the triad will contain more than three tones. Major triads consist of intervals of a major third (four semitones) and a perfect fifth (seven semitones) with respect to a reference pitch (the root). In a minor triad, the third is minor (three semitones), and in diminished triads, the third is minor and the fifth is diminished (six semitones). In the major keys, some of these triads are major (I, IV, and V), while others are minor (ii, iii, vi), and the last is diminished (vii $\left.{ }^{\circ}\right)$. Often, a fourth note, 10 semitones above the root, is added to chord $\mathrm{V}$, making a dominant seventh. A fourth note, 10 semitones above the root, also may be added to chord ii, iii, or vi, making minor seventh chords.

Triads that are built on the first (tonic), the fifth (dominant), and the fourth (subdominant) scale degrees usually have a more central syntactic function than those built on the other scale degrees, creating a within-key hierarchy. Between-key distances refer to the distances separating the 24 major and minor keys. Keys sharing a great number of scale notes ( $C$ and $G$ major or $C$ major and $A$ minor, for example) are very close, while those sharing only a few tones are very far apart ( $\mathrm{C}$ major and $\mathrm{F} \#$ major, or $\mathrm{C}$ major and $\mathrm{Eb}$ minor, for example).

A number of experimental studies have shown that listeners, even inexperienced ones, have internalized the main aspects of within-key hierarchies and between-key distances (Dowling \& Harwood, 1986; Francès, 1958; Krumhansl, 1990). From this knowledge they are able, ideally, to confer a specific tonal function on each event of a musical piece (Bigand, 1993a; Francès, 1958; Lerdahl \& Jackendoff, 1983). Perceived musical tension is assumed to be related to tonal function: important events in a tonal hierarchy instill weak or null musical tension, and less important ones create strong musical tension. The first purpose of the present study was to confirm this relation with short chord sequences. Consider the musical fragment in $\mathrm{C}$ major shown in Figure 1 . The perceived tension created by the second chord should be nil in la because this chord is a tonic chord, low in $1 \mathrm{~b}$ because this chord is a hierarchi- 


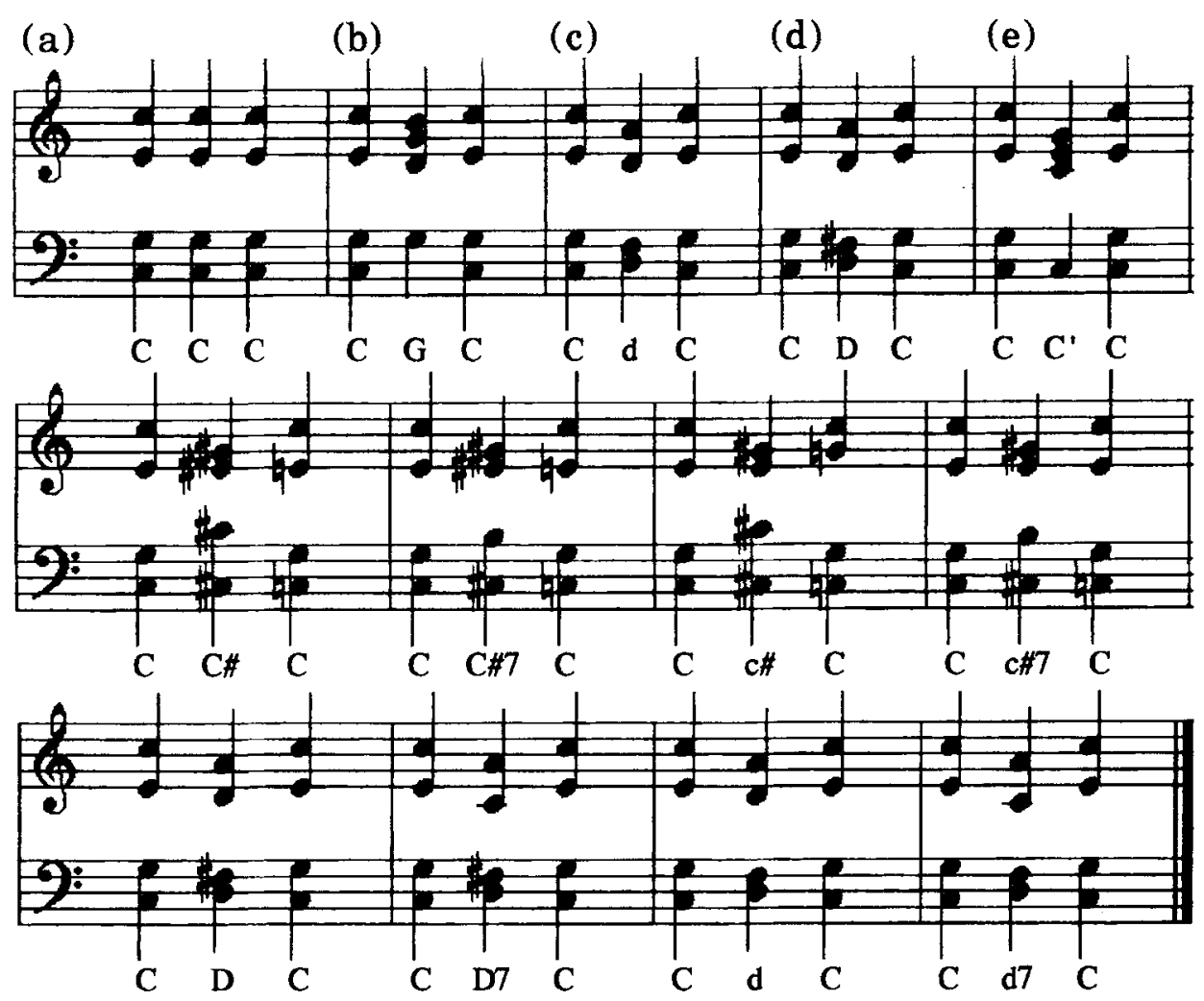

Figure 1. Examples of three-chord sequences used in the experiment. Chord sequences $(a, b, c, d, e)$ illustrate how musical tension varies with harmonic function and with horizontal motion.

cally important dominant chord, higher in $1 \mathrm{c}$ because the chord is built on a less important second scale degree, and still higher in $1 \mathrm{~d}$ because it is a nondiatonic chord. Hence we would predict that musical tension will be higher when the second triad is nondiatonic and that the perceived tension will be negatively correlated with the perceived harmonic hierarchies measured by Krumhansl (1990, Table 7.3).

Predicting musical tension from the tonal pitch space theory. The psychological representation of tonal space has been described in various ways (LonguetHiggins, 1978; Shepard, 1982; see also Krumhanst \& Kessler, 1982). In all these approaches, tonal hierarchies are represented in the form of a multidimensional space in which the distances of chords from the instantiated tonic correspond their relative hierarchical importance. The more important the chords, the smaller the distances. The tonal pitch space theory, developed by Lerdahl (1988), follows these approaches in a more systematic way by defining a formula for computing psychological distances between musical objects. The basic idea is to represent the tonal hierarchies in three embedded spaces, the two first representing within-key hierarchies, and the third one the betweenkeys distances.

The first space is called pitch-class proximity. This space contains five levels: 1 , chromatic; 2 , diatonic; 3 , triadic; 4 , fifth; and 5, root. In a given context, a tonic tone in a tonic triad will be represented at all five levels, a dominant tone in a tonic triad at the fifth (fifth above the root) and all lower levels, the third of the tonic triad at the triadic and all lower levels. A nonchordal (but still diatonic) tone will be represented at the diatonic and chromatic levels, and a nondiatonic tone at the chromatic level only. For the purpose of the present study, Lerdahl's (1988) theory was expanded to discriminate between triads and seventh chords. The seventh of a chord, like the third, is represented in pitch-class proximity at the triadic level. Therefore, adding a seventh to a triad produces one change in pitch-class proximity if the seventh belongs to the key, two changes if it is a nondiatonic tone. For example, adding a seventh to the $G$ dominant chord produces one change because the $F$ tone is transferred from the diatonic level to the triadic level. Adding a seventh to a subdominant $F$ chord produces two changes in pitch-class proximity because the nondiatonic $E b$ tone is transferred from the first level (chromatic) to the third (triadic).

The second space is called chord proximity within a key (or region). The formula computes the distances separating the seven diatonic chords, taking into account the number of steps that separate the roots of the chords on the diatonic fifth circle (C-G-D-A-E-B-F) and the number of changes in pitch-class proximity created by the second chord. Let us consider the distance between the triads $C$ and $G$ in a $C$ major context. In a $C$ major triad, $G$ is the fifth and is therefore represented at Level 4 . In a $G$ major triad, $\mathrm{G}$ is the root and is therefore represented at Level 5. 
This shift in function of G from Level 4 to Level 5 introduces one change in pitch-class proximity. Similarly, the shift in function of $\mathrm{D}$ from Level 2 (diatonic tone in a $\mathrm{C}$ major triad context) to Level 4 (the fifth in a G triad) introduces two changes in pitch-class proximity. Consequently, in a $\mathrm{C}$ major context, the distance between the chords $C$ and $G$ equals 5 , because the $G$ chord introduces four changes in pitch-class proximity (i.e., $G$ goes from Level 4 to Level 5, D from Level 2 to Level 4, and B from Level 2 to Level 3 ) and because there is one step that separates the $\mathrm{C}$ and the $\mathrm{G}$ chords on the diatonic fifths circle. If the $\mathrm{G}$ chord had contained a seventh, this distance would have been six.

The third space concerns the distances between keys or regions. The purpose of Lerdahl's formula at this level is not only to compute the distances between tonic chords of different regions, but also to compute distances between chords of one region to chords of another region. The formula computes the distances separating the regions, taking into account the number of steps separating two regions on the chromatic fifths' circle ( $\mathrm{C}-\mathrm{G}-\mathrm{D}-\mathrm{A}-\mathrm{E}-\mathrm{B}-\mathrm{F} \#-\mathrm{C} \#$ or $\mathrm{D} b-\mathrm{A} b-\mathrm{E} b-\mathrm{B} b-\mathrm{F})$ and the number of changes in chord proximity and in pitch-class proximity produced by this change of key. For example, the distance between the tonics of the $\mathrm{C}$ and the $\mathrm{G}$ regions equals 7 because there is one step separating these regions on the chromatic fifths circle, five changes in chord-class proximity, and one more change in pitch-class proximity because the $F$ in $\mathrm{G}$ major and a nondiatonic one in the $\mathrm{C}$ major key.

Specific harmonic progressions follow specific paths through pitch space (Lerdahl, 1991). Lerdahl hypothesizes that greater spatial distances between musical events correspond to greater degrees of perceived musical tension. This hypothesis is a cognitive one, because the computed distances between two events depend entirely on the tonal function that is conferred on them. Consider, for example, the chord sequence 1d (Figure 1). If the second chord is interpreted as a tonic chord of $\mathrm{D}$ major, its pitch space distance from the $\mathrm{C}$ chord will be 14 , since there is a pitch space distance of seven between the $C$ and $G$ regions plus a distance of seven between the $G$ and $D$ regions (see Lerdahl, 1988, for a complete account). As this chord belongs to several other keys as well, it can of course receive other interpretations. For example, if it is considered as a dominant chord of the $\mathrm{G}$ key, its tonal distance from the $\mathrm{C}$ chord will be shorter since $\mathrm{C}$ and $\mathrm{G}$ regions are closer than $\mathrm{C}$ and $\mathrm{D}$ regions. In this case, the pitch space distance will be 10 (i.e., one step to go from $\mathrm{C}$ to $\mathrm{G}$ on the (regional) chromatic fifths' circle, two steps between the C and D chords on the (chordal) diatonic fifths' circle, and seven changes in pitch-class commonality). The theory thus formalizes the different possible interpretations that musical events can receive. The problem arises, however, in specifying which one will be preferred by listeners in a given case. With long chord sequences, the global structure of the piece strongly constrains the interpretation of the chord function. With short chord sequences, the musical interpretation is less clear. In general, listeners are assumed to follow a simple economical principle, that of perceiving chords in a way that minimizes their distances from the main tonic chord. Table 1 displays the distances in tonal pitch space computed according to this principle of "the shortest path" for all the chords used in this study in reference to the tonic chord of the $\mathrm{C}$ major key.

\section{Sensory Models of Musical Tension}

In contrast to cognitive approaches to tension, psychoacoustical theories predict the strength of harmonic pitch relationships between successive chords without considering the listener's implicit knowledge of tonality. A further goal of the study was to investigate two distinct sensory aspects of musical tension: the calculated roughness of individual chords, and the calculated pitch commonality between successive chords.

Roughness and dissonance of individual chords. Perhaps the most apparent factor that might contribute to the perceived tension of a musical chord is sensory dissonance when the chord is presented in isolation. According to Helmholtz (1877, chap. 10), the dissonance of a chord depends on its perceived roughness. Plomp and Levelt (1965) showed that the contribution to the roughness of a sound from a pair of pure-tone components is greatest when the distance between the components corresponds approximately to one quarter of a critical band, where critical bandwidth lies in the approximate range $10 \%-20 \%$ of center frequency, or roughly two to three semitones, for center frequencies above about $500-1000 \mathrm{~Hz}$ and in the approximate range of $50-100 \mathrm{~Hz}$ at lower frequencies (Moore \& Glasberg, 1983; Plomp \& Levelt, 1965; Zwicker \& Terhardt, 1980).

Hutchinson and Knopoff (1978) formalized the findings of Plomp and Levelt (1965) in such a way that they may be applied to musical chords, on the assumption that each note of the chord has equal amplitude and contains 10 harmonics tuned to equal temperament, whose amplitudes are proportional to the reciprocal of their harmonic number $(1 / n)$. We formulated the model of Hutchinson and Knopoff and applied it to all the chords presented in the experiment (Table 2). We chose this model because it is relatively straightforward to apply, and because it appears to encapsulate the most important effects of roughness in typical chord progressions. The present implementation of Hutchinson and Knopoff's algorithm was identical to theirs, with the following minor exception: Hutchinson and Knopoff sampled the "standard curve" of Plomp and Levelt, reducing it to a look-up table for computational purposes. In the present implementation, the "standard curve" of Plomp and Levelt was closely approximated by the following analytic function:

$$
\begin{aligned}
& g(x)=[(\operatorname{ex} / a) \exp \{-x / a\}]^{i}, x<1.2 \\
& g(x)=0, x>1.2
\end{aligned}
$$

where $e$ is the base of natural logarithms $(e=2.72), x$ is the interval between two partials expressed in critical bandwidths, $a$ is the interval in critical bandwidths for maxi- 
Table 1

Tonal Pitch Space Distances Computed for the 50 Chords From I/C

\begin{tabular}{|c|c|c|c|c|c|}
\hline \multicolumn{3}{|c|}{ Shortest } & \multicolumn{3}{|c|}{ Shortest } \\
\hline Chords & Path & Distance & Chords & Path & Distance \\
\hline $\mathrm{C}$ & $\mathrm{I} / \mathrm{C}$ & 0 & $\mathrm{c}$ & $i / c$ & 7 \\
\hline$C \#$ or Db & $\mathrm{IV} / \mathrm{Ab}$ & 16 & $\mathrm{c} \#$ or $\mathrm{db}$ & iv/ab & 20 \\
\hline D & $\mathrm{V} / \mathrm{G}$ & 10 & $\mathrm{~d}$ & $\mathrm{ii} / \mathrm{C}$ & 8 \\
\hline$D \#$ or $E$ ? & $111 / \mathrm{c}$ & 14 & $\mathrm{~d} \#$ or eb & $\mathrm{iv} / \mathrm{bb}$ & 18 \\
\hline E & $\mathrm{V} / \mathrm{a}$ & 10 & $\mathrm{e}$ & $\mathrm{iii} / \mathrm{C}$ & 7 \\
\hline $\mathbf{F}$ & IV/C & 5 & $f$ & $\mathrm{iv} / \mathrm{c}$ & 12 \\
\hline $\mathrm{F} \#$ & $\mathrm{~V} / \mathrm{iii} / \mathrm{G}$ & 18 & $\mathrm{f} \#$ & $\mathrm{iii} / \mathrm{V} / \mathrm{G}$ & 18 \\
\hline $\mathrm{G}$ & $\mathrm{V} / \mathrm{C}$ & 5 & $\mathrm{~g}$ & $\mathrm{iv} / \mathrm{d}$ & 9 \\
\hline $\mathrm{G} \#$ or $\mathrm{A}$ & $\mathrm{VI} / \mathrm{c}$ & 14 & $g \#$ & $\mathrm{iii} / \mathrm{E}$ & 23 \\
\hline A & $\mathrm{V} / \mathrm{d}$ & 11 & $\mathrm{a}$ & $\mathrm{vi} / \mathrm{C}$ & 7 \\
\hline $\mathrm{A} \#$ or $\mathrm{B}$ b & $\mathrm{IV} / \mathrm{F}$ & 10 & $\mathrm{bb}$ & $\mathrm{iv} / \mathrm{f}$ & 16 \\
\hline B & $\mathrm{V} / \mathrm{e}$ & 13 & $\mathrm{~b}$ & $\mathrm{iii} / \mathrm{G}$ & 11 \\
\hline $\mathrm{C}^{7}$ & $\mathrm{~V} / \mathrm{C}$ & 2 & $c^{7}$ & $i / c$ & 9 \\
\hline $\mathrm{C} \#^{7}$ or $\mathrm{D}^{\top}$ & IV/A b & 17 & $c^{\$ 7}$ or $\mathrm{d}^{7}$ & iv/ab & 21 \\
\hline $\mathrm{D}^{7}$ & $\mathrm{~V} / \mathrm{G}$ & 11 & $d^{7}$ & $\mathrm{ii} / \mathrm{C}$ & 9 \\
\hline$D \#^{7}$ or $E b^{7}$ & $\mathrm{IIV} / \mathrm{c}$ & 16 & $d \#^{7}$ or $e^{b^{7}}$ & $\mathrm{iv} / \mathrm{bb}$ & 20 \\
\hline $\mathrm{E}^{7}$ & $\mathrm{~V} / \mathrm{a}$ & 11 & $e^{7}$ & $\mathrm{iii} / \mathrm{C}$ & 8 \\
\hline$F^{7}$ & $\mathrm{IV} / \mathrm{C}$ & 7 & $f^{7}$ & iv $/ \mathrm{c}$ & 14 \\
\hline$F \# 7$ & $\mathrm{~V} / \mathrm{iii} / \mathrm{G}$ & 19 & $\mathrm{f} \# 7$ & $\mathrm{iii} / \mathrm{V} / \mathrm{G}$ & 19 \\
\hline $\mathrm{G}^{7}$ & $\mathrm{~V} / \mathrm{C}$ & 6 & $\mathrm{~g}^{7}$ & iv/d & 10 \\
\hline $\mathrm{G}^{7} 7$ or $\mathrm{A} b^{7}$ & $\mathrm{VI} / \mathrm{c}$ & 16 & $g \# 7$ & $\mathrm{iii} / \mathrm{E}$ & 24 \\
\hline$A^{7}$ & $\mathrm{~V} / \mathrm{d}$ & 12 & $a^{7}$ & $\mathrm{vi} / \mathrm{C}$ & 8 \\
\hline$A \# 7$ or $B b$ ? & $\mathrm{IV} / \mathrm{F}$ & 12 & $b b^{7}$ & $\mathrm{iv} / \mathrm{f}$ & 18 \\
\hline $\mathrm{B}^{7}$ & $\mathrm{~V} / \mathrm{e}$ & 14 & $b^{7}$ & $\mathrm{iii} / \mathrm{G}$ & 12 \\
\hline$b^{\circ}$ & $\mathrm{vii}^{\circ} / \mathrm{C}$ & 8 & & & \\
\hline $\mathrm{C}^{\prime}$ & $\mathrm{I} / \mathrm{C}$ & 0 & & & \\
\hline
\end{tabular}

Note $-\mathrm{I} / \mathrm{C}$, tonic chord of the $\mathrm{C}$ major key. Roman numerals represent scale degrees. Uppercase letters represent major triads; lowercase, minor. Chord symbols " 7 " represent major-minor seventh.

mum roughness (where $a=0.25$, according to Plomp and Levelt), and $i$ is an arbitrary index (we set $i=2$ to fit the shape of the standard curve). In the foregoing, critical bandwidth is in all cases calculated according to Plomp and Levelt's equation for critical bandwidth, since the value $a=0.25$ was estimated relative to that function.

As shown in Table 2, chords with minor thirds have systematically greater roughness than chords with major thirds, provided that voicing, register, and spectral content are held constant similarly. Chords with sevenths systematically have greater roughness than chords without sevenths. These values led us to the following two hypotheses: (1) Minor chords will be, on the average, associated with more tension than major chords. (2) Seventh chords will be associated with more tension than triads. These hypotheses are in qualitative agreement with music theory.

The model of Hutchinson and Knopoff (1978) neglects certain important aspects of roughness perception. For example, it neglects mutual masking of pure-tone components, the dependency of the roughness of a pair of beating, pure-tone components on their absolute (mean) frequency, and the role of critical bands in the summation of different contributions to overall roughness (for details, see Aures, 1985; Terhardt, 1974a). The model of Hutchinson and Knopoff also assumes that contributions to overall roughness add linearly, an assumption that has been questioned by Kameoka and Kuriyagawa (1969) and Vos (1986). In the present application of the model, however, we are only concerned to compare the roughness of chords containing a constant number of tones in a similar pitch register. Under these circumstances, we expected the model of Hutchinson and Knopoff to give a reasonable indication of the relative roughness of the various chords. We also expected the model to account for the small variations in voicing (spacing, doubling) that occurred among the experimental stimuli.

Pitch commonality of successive chords. In the mainstream theory of tonal harmonic music, successive chords are considered to stand in a strong harmonic relationship with each other if they satisfy one or more of the following conditions: (1) They have one or more tones in common, (2) their roots are close to each other on the cycle of fifths, and (3) their notes all belong to the same major or minor scale.

Of these three, only the first (the notes in common condition) can be unequivocally defined and applied to any chord sequence. A problem with the cycle of fifths condition is that the roots of chords are generally somewhat ambiguous (Parncutt, 1988; Terhardt, 1974b), so distance on the cycle of fifths is not always clearly defined. A problem with the scale-belongingness condition is that it is not always clear which pitches belong to the prevailing scale and which do not-for example, if there is a modulation taking place, or if the ambiguous sixth and seventh degrees of the minor scale are involved. Moreover, some major- 
Table 2

Calculated Roughness Values According to Hutchinson and Knopoff (1978) and Pitch Commonality Values According to Parncutt (1989) for the 50 Chords Used in the Experiment

\begin{tabular}{|c|c|c|c|c|c|}
\hline Chords & $\begin{array}{l}\text { Roughness } \\
\text { Values }\end{array}$ & $\begin{array}{c}\text { Pitch } \\
\text { Commonality }\end{array}$ & Chords & Roughness & Pitch \\
\hline $\mathrm{C}$ & 109 & 1.00 & $C^{7}$ & .124 & .72 \\
\hline $\mathrm{C} \#$ or $\mathrm{Db}$ & .072 & -.10 & $\mathrm{C} \#^{7}$ or $\mathrm{Db}^{7}$ & .168 & -.10 \\
\hline D & .108 & -.02 & $\mathrm{D}^{7}$ & .20 & .29 \\
\hline $\mathrm{D} \#$ or $\mathrm{Eb}$ & .103 & .12 & $\mathrm{D} \# 7$ or $E b^{7}$ & .191 & .09 \\
\hline $\mathrm{E}$ & .098 & .13 & $E^{7}$ & .182 & .02 \\
\hline $\mathbf{F}$ & .065 & .32 & $F^{7}$ & .186 & .07 \\
\hline$F \#$ or $G b$ & .061 & -.12 & $\mathrm{~F}^{\# 7}$ or $\mathrm{G} b^{7}$ & .157 & .02 \\
\hline $\mathrm{G}$ & .057 & .32 & $\mathrm{G}^{7}$ & .149 & .21 \\
\hline$G \#$ or $A b$ & .119 & .18 & $G \#^{7}$ or $A b^{7}$ & .204 & .15 \\
\hline A & .112 & .12 & $\mathrm{~A}^{7}$ & .192 & .36 \\
\hline$A \#$ or $B$ & .106 & .01 & $A \#^{7}$ or $B b^{7}$ & .182 & -.02 \\
\hline B & .099 & .12 & $\mathrm{~B}^{7}$ & .171 & -.11 \\
\hline c & .145 & .83 & $d^{7}$ & .147 & .45 \\
\hline$c \#$ or $d b$ & .093 & .00 & $c \#^{7}$ or $d b^{7}$ & .161 & .05 \\
\hline d & .132 & .06 & $d^{7}$ & .189 & .33 \\
\hline$d \#$ or eb & .124 & -.09 & $d \#^{7}$ or e $b^{7}$ & .18 & -.13 \\
\hline $\mathrm{e}$ & .117 & .38 & $e^{7}$ & .171 & .29 \\
\hline f & .116 & .24 & $\mathrm{f}^{7}$ & .194 & .04 \\
\hline$f \#$ or $g b$ & .111 & -.10 & $f \#^{7}$ or $g b^{7}$ & .185 & .07 \\
\hline g & .105 & .39 & $g^{7}$ & .176 & .21 \\
\hline $\mathrm{g} \#$ or ab & .123 & -.12 & $g \# 7^{7}$ or $a b^{7}$ & .186 & -.14 \\
\hline a & .115 & .46 & $a^{7}$ & .175 & .75 \\
\hline$a \#$ or $b b$ & .108 & -.09 & $a \#^{7}$ or $b b^{7}$ & .165 & -.11 \\
\hline $\mathrm{b}$ & .102 & -.06 & $b^{7}$ & .155 & -.05 \\
\hline$b^{\circ}$ & .163 & -.02 & & & \\
\hline$C^{\prime}$ & .077 & .91 & & & \\
\hline
\end{tabular}

Note-Uppercase letters represent major triads; lowercase, minor. Chord symbols " 7 " represent major-minor seventh.

minor scale degrees are clearly more perceptually important than others (Krumhansl \& Kessler, 1982).

The sensory model of Parncutt (1989) predicts the strength of harmonic pitch relationships between successive chords, without invoking music-theoretic constructs such as the cycle of fifths and the harmonic/melodic minor scales. The model does not directly account for the listener's implicit or explicit knowledge of tonality. Instead, predictions are based entirely on the degree to which the two chords have perceived pitches in common, taking into account the relative perceptual saliences of each pair of pitches.

The perceived pitches of a chord do not correspond in a one-to-one fashion with either its notated pitches or the frequencies of its pure-tone components (Parncutt, 1989; Terhardt, 1974a, 1974b). For example, an E-flat major triad may weakly imply the pitch $\mathrm{C}$, even though that pitch is not notated, and may not even be physically present. This "implied pitch" may contribute to the perceived relationship between the triads E-flat major $(E b-G-B b)$ and $C$ major $(\mathrm{C}-\mathrm{E}-\mathrm{G})$. Of course the most important contribution to this particular relationship is the common note $\mathrm{G}$.

Implied pitches are sometimes so weak that it would be impossible to demonstrate their existence in a psychoacoustic experiment. However, any algorithm that inputs only the information available to the auditory system and outputs all possible pitches that could be perceived (as fundamentals of complex tones) will predict these implied pitches, including algorithms based on temporal analysis of the signal. In general, and in the present study in particular, pitches in musical chords that are implied but not notated are assumed in principle to be consciously perceptible, but to be perceived much less often than actual pitches, in accordance with their lower calculated saliences. Moreover, we assume that trained musicians are less likely than nonmusicians to confuse implied pitches with actual pitches, owing to their extensive experience of the relationship between notated and heard music.

The pitch-commonality model may be divided up into two stages. The input to the first stage is the amplitude spectrum of each chord, and the output is a profile of the (virtual) pitches and predicted saliences of individual tone sensations evoked by each chord. The salience of a virtual pitch depends on the number and salience of spectral pitches approximating a harmonic series above that pitch. Virtual pitches do not necessarily correspond to notes actually played but may be implied by other pitches. The strongest virtual pitches in the bass region of a chord often correspond to possible roots. The model that we use here (Parncutt, 1989) is not octave generalized, so the profile output by the first stage of the model extends across the entire audible pitch range.

The second stage of the model compares successive pairs of pitch profiles, and outputs a value called pitch 
commonality (Table 2). Here, pitch commonality is simply a correlation coefficient between two profiles, calculated over 120 pitch categories, or 10 octaves of the chromatic scale. For the purpose of the present study, we hypothesize that chords whose harmonic relationship to the tonic triad is weak evoke more tension than do chords whose harmonic relationship to the tonic triad is strong, and that pitch commonality provides an appropriately accurate measure of harmonic relationship. Consider, for example, the chords $\mathrm{C}$ major and $\mathrm{G}$ major (Figure $1 \mathrm{~b}$ ). In the first stage, the $\mathrm{C}$ chord evokes strong virtual pitches corresponding to the notes $\mathrm{C}, \mathrm{E}$, and $\mathrm{G}$ (where $\mathrm{C}$ is typically the strongest), plus weak subsidiary pitches at $\mathrm{F}$ and A. The pitch $F$ lies a perfect fifth below $C$, and so, with octave generalization, it corresponds to the 3 rd subharmonic of $\mathrm{C}$. $\mathrm{F}$ also corresponds to the 9th subharmonic of $\mathrm{G}$. Similarly, $A$ is the 3 rd subharmonic of $E$ as well as the 7 th subharmonic of $G$. The main virtual pitches of the $G$ chord are the notes $G, B$, and D, and the subsidiary pitches include $\mathrm{C}$ and $\mathrm{E}$. The pitch commonality of the two chords involves not only the common note $\mathrm{G}$, but also the common pitches $\mathrm{C}$ and $\mathrm{E}$. The feeling of "forward progression" from the $\mathrm{G}$ chord to the $\mathrm{C}$ chord may perhaps involve the pitches $\mathrm{C}$ and $\mathrm{E}$, which are implied by the first chord and realized in the second. In the present study, the pitch commonality of the two chords is formulated as a correlation coefficient between the calculated saliences of all pitches evoked by the first chord and the saliences of the pitches evoked by the second. Thus, pitch commonality involves both the evoked pitches and their calculated salience.

\section{Horizontal Motion}

The cognitive and sensory approaches described above emphasize the effect of harmony-the vertical arrangement of the tones - on musical tension. The effect of the melodic arrangement between the tones of successive chords is neglected by these models. According to many music theorists, this horizontal organization is an equally important factor influencing the structure of chord progressions. Good horizontal organization is produced by adhering to a number of more or less strict rules, referred to as counterpoint rules in pedagogical treatises. For example, smoother progressions occur when there are small intervals between each voice of successive chords. Certain large intervals are avoided within a single voice because they weaken the linear continuity of the chord progressions (Bitsch, 1957). Music-theoretic controversies concerning the relative importance of the vertical and horizontal dimensions in harmonic progressions have a long history. There is, however, agreement that horizontal motion affects the consonance of the chords. For example, a seventh chord should be perceived as less dissonant if the seventh is prepared - that is, heard in the previous chordin the same voice.

Several empirical studies have supported the importance of horizontal organization on music perception (Dowling, 1978; Dowling \& Hollombe, 1977; see Dowling \& Harwood, 1986, for a review). Experiments per- formed by Carlsen (1981; Unyk \& Carlsen, 1987) notably revealed that participants required to complete a melodic fragment tend to produce tones close in pitch to the last tone of the fragment. Melodic features influence the way a tone fits perceptually with its previous context (Schmuckler, 1989) and the anchoring of unstable musical events in short melodies (Bharucha, 1984). In the case of chord progressions, Krumhansl (1990) reported that melodic factors can influence perceived tonal hierarchies. In order to minimize the effect of melodic motion, Krumhansl, Bharucha, and Kessler (1982) and Kwak (1994) used Shepard tones (Shepard, 1964). Finally, research on auditory scene analysis provided some psychoacoustical explanations of the influence of horizontal organization on the perception of chord sequence (Bregman, 1990).

The final goal of this study was to investigate the effect of horizontal organization on perceived musical tension. Let us consider the two short chord sequences la and $1 \mathrm{e}$ in Figure 1. From a purely harmonic point of view, the second chord creates no harmonic tension in each sequence. But because the horizontal motion differs in the tenor and soprano voices in Sequence le, we can assume that the perceived musical tension will be higher for the second chord. The contribution of horizontal motion to musical tension was predicted in this study by computing the sizes of the intervals covered by each voice when passing from one chord to the next. In the case of the sequence la, there is no horizontal motion, so each voice receives the value 0 . In the case of the sequence le, however, the tenor and the soprano voices, both traverse an interval of 5 semitones. These voices receive the value 5 , and the others the value 0 . The quantification of horizontal motion for all chord sequences is displayed in Table 3 . Over all the sequences, the voices that move the least are the alto and the soprano.

In summary, we have seen that several theoretical variables can affect the tension perceived in chord progressions. The variables differ in the extent to which they are cognitive or sensory, suggesting that some may be more important for musicians and some for nonmusicians. Thus the testing of these variables also provides an opportunity to investigate the effects of musical training.

\section{METHOD}

\section{Participants}

Fourteen students in the music conservatory of Troyes (France) who were finishing their studies in music theory, ear training, and instrumental performance (referred to henceforth as musicians) participated in the experiment. Fourteen musically naive students of the same age who were studying psychology at Dijon University (referred to henceforth as nonmusicians) also performed the experiment.

\section{Materials}

Examples of the three-chord sequences used in the experiment are shown in Figure 1. The first and the last chords were always $\mathrm{C}$ major, in order to encourage the listeners to perceive the second chord in a way that minimized its pitch space distance from the $\mathrm{C}$ major chord. The repetition of the tonic chord was also assumed to eliminate the effect of asymmetry (Bharucha \& Krumhansl, 1983; Krumhansl, 1979) and to maintain the feeling of the $C$ major key throughout all the experiment. The root of the second chord was transposed to cor- 
Table 3

Horizontal-Motion Values Computed for Each Voice in the 50 Chord Sequences Used in the Experiment

\begin{tabular}{|c|c|c|c|c|c|c|c|c|c|}
\hline Sequence & Bass & Tenor & Alto & Soprano & Sequence & Bass & Tenor & Alto & Soprano \\
\hline $\mathrm{C}-\mathrm{C}-\mathrm{C}$ & 0 & 0 & 0 & 0 & $C-C^{7}-C$ & 0 & 0 & 0 & 2 \\
\hline $\mathrm{C}-\mathrm{C} \#-\mathrm{C}$ & 1 & 6 & 1 & 4 & $\mathrm{C}-\mathrm{C} \#{ }^{7}-\mathrm{C}$ & 1 & 3 & 1 & 4 \\
\hline C-D $-C$ & 2 & 1 & 2 & 3 & $C-D^{7}-C$ & 2 & 1 & 4 & 3 \\
\hline $\mathrm{C}-\mathrm{D} \#-\mathrm{C}$ & 3 & 0 & 1 & 2 & $\mathrm{C}-\mathrm{D} \#^{7}-\mathrm{C}$ & 3 & 0 & 3 & 2 \\
\hline $\mathrm{C}-\mathrm{E}-\mathrm{C}$ & 4 & 1 & 0 & 1 & $C-E^{7}-C$ & 4 & 1 & 2 & 1 \\
\hline $\mathrm{C}-\mathrm{F}-\mathrm{C}$ & 5 & 5 & 1 & 3 & $\mathrm{C}-\mathrm{F}^{7}-\mathrm{C}$ & 5 & 8 & 1 & 3 \\
\hline $\mathrm{C}-\mathrm{F} \#-\mathrm{C}$ & 6 & 6 & 2 & 2 & $\mathrm{C}-\mathrm{F} \#{ }^{7}-\mathrm{C}$ & 6 & 6 & 0 & 2 \\
\hline $\mathrm{C}-\mathrm{G}-\mathrm{C}$ & 7 & 7 & 3 & 1 & $\mathrm{C}-\mathrm{G}^{7}-\mathrm{C}$ & 7 & 7 & 1 & 1 \\
\hline $\mathrm{C}-\mathrm{Ab}-\mathrm{C}$ & 8 & 5 & 1 & 4 & $C-A b^{7}-C$ & 8 & 5 & 1 & 6 \\
\hline $\mathrm{C}-\mathrm{A}-\mathrm{C}$ & 9 & 6 & 0 & 3 & $\mathrm{C}-\mathrm{A}^{7}-\mathrm{C}$ & 9 & 6 & 0 & 5 \\
\hline $\mathrm{C}-\mathrm{B} b-\mathrm{C}$ & 10 & 7 & 1 & 2 & $\mathrm{C}-\mathrm{B} b^{7}-\mathrm{C}$ & 10 & 7 & 1 & 4 \\
\hline $\mathrm{C}-\mathrm{B}-\mathrm{C}$ & 11 & 8 & 2 & 1 & $C-B^{7}-C$ & 11 & 8 & 2 & 3 \\
\hline $\mathrm{C}-\mathrm{c}-\mathrm{C}$ & 0 & 0 & 1 & 0 & $C-c^{7}-C$ & 0 & 0 & 1 & 2 \\
\hline$C-c \#-C$ & 1 & 6 & 0 & 4 & $\mathrm{C}-\mathrm{c} \# 7-\mathrm{C}$ & 1. & 3 & 0 & 4 \\
\hline $\mathrm{C}-\mathrm{d}-\mathrm{C}$ & 2 & 2 & 2 & 3 & $\mathrm{C}-\mathrm{d}^{7}-\mathrm{C}$ & 2 & 2 & 4 & 3 \\
\hline $\mathrm{C}-\mathrm{d} \#-\mathrm{C}$ & 3 & 1 & 1 & 2 & $\mathrm{C}-\mathrm{e} \# 7-\mathrm{C}$ & 3 & 1 & 3 & 2 \\
\hline $\mathrm{C}-\mathrm{e}-\mathrm{C}$ & 4 & 0 & 0 & 1 & $C-e^{7}-C$ & 4 & 0 & 2 & 1 \\
\hline$C-f-C$ & 5 & 5 & 1 & 4 & $\mathrm{C}-\mathrm{f}^{7}-\mathrm{C}$ & 5 & 8 & 1 & 4 \\
\hline $\mathrm{C}-\mathrm{f} \#-\mathrm{C}$ & 6 & 6 & 2 & 3 & $\mathrm{C}-\mathrm{f} \#^{7}-\mathrm{C}$ & 6 & 6 & 0 & 3 \\
\hline $\mathrm{C}-\mathrm{g}-\mathrm{C}$ & 7 & 7 & 3 & 2 & $\mathrm{C}-\mathrm{g}^{7}-\mathrm{C}$ & 7 & 7 & 1 & 2 \\
\hline$C-a b-C$ & 8 & 4 & 1 & 4 & $C-a b^{7}-C$ & 8 & 3 & 1 & 6 \\
\hline $\mathrm{C}-\mathrm{a}-\mathrm{C}$ & 9 & 5 & 0 & 3 & $C-a^{7}-C$ & 9 & 5 & 0 & 5 \\
\hline $\mathrm{C}-\mathrm{b} b-\mathrm{C}$ & 10 & 6 & 1 & 2 & $C-b b^{7}-C$ & 10 & 6 & 1 & 4 \\
\hline $\mathrm{C}-\mathrm{b}-\mathrm{C}$ & 11 & 7 & 2 & 1 & $C-b^{7}-C$ & 11 & 7 & 2 & 3 \\
\hline $\mathrm{C}-\mathrm{b}^{\circ}-\mathrm{C}$ & 11 & 7 & 1 & 1 & & . & & & \\
\hline $\mathrm{C}-\mathrm{C}^{\prime}-\mathrm{C}$ & 0 & 5 & 0 & 5 & & & & & \\
\hline Means & 5.5 & 4.32 & 1.22 & 2.72 & & & & & \\
\hline Range & 11 & 8 & 4 & 6 & & & & & \\
\hline
\end{tabular}

Note-Uppercase letters represent major triads; lowercase, minor. Chord symbols " 7 " represent major-minor seventh.

respond to all 12 tones of the chromatic scale, and the quality of the chord was a major triad, a major-minor seventh chord, a minor triad, or a minor-minor seventh chord, making a total of $12 \times 4=48$ trials. Two additional trials were used: one containing a $\mathrm{B}$ diminished triad $\left(b^{\circ}\right)$, the other a $C$ major triad in a different voicing $\left(C^{\prime}\right)$. The voice leading was carefully controlled in all sequences. The outer voices always moved in contrary motion, the bass rising and the soprano falling from the first chord to the second. Intervals covered by the tenor and alto voices were made as small as possible. Parallel octaves and fifths were avoided where possible.

In order to instill a strong feeling of the $\mathrm{C}$ major key, each trial was preceded by a short passage in $\mathrm{C}$ major. This passage was a short harmonic progression during the familiarization part of the experiment, and a short melody in $\mathrm{C}$ major during the test part (Figure 2). The stimuli were played with sampled piano sounds produced by the Yamaha EMT10 Sound Expander at a tempo of 90 quarter notes per minute (interonset interval between chords equal to $667 \mathrm{msec}$ ). The Yamaha sampler was controlled through a MIDI interface, by a Macintosh computer running Performer software. Velocity, a parameter related to the force with which a key is struck, was constant for all the pitches. Participants were allowed to adjust the output of the amplifier to a comfortable level. There was no silence between offsets and onsets of successive chords.

\section{Task}

The participant's task was to rate the tension produced by the second chord of each trial on a 12-point scale, ranging from 1 (weak) to 12 (strong). Some examples were given beforehand, in order to familiarize the participants with the notion of musical tension.

\section{Procedure}

In the first part of the experiment (familiarization), the participants performed 20 trials randomly chosen from the 50 that were to be used ( $48+2$ trials). No feedback was given, except if they used the rating scale in the reverse order. In the second part (experiment proper), each participant heard the 50 trials twice, in two separate blocks. For each participant, and in each block, the trials were presented in random order. The experiment took $45 \mathrm{~min}$.

\section{RESULTS}

\section{Agreement Between Participants}

To assess the consistency of the data, correlations between the first and second blocks were computed for each participant. All the correlations were statistically significant $(p<.05)$. The correlation between the mean ratings for the first and the second block was .92 for the musicians and .88 for the nonmusicians. Thereafter the data were collapsed across blocks. To assess the degree of agreement between the participants, the Kendall coefficient of concordance was computed for both groups. Kendall coefficients were significant for both musicians ( $W=.58$, $p<.01$ ) and nonmusicians ( $W=.54, p<.01$ ), indicating a significant agreement among the participants. The correlation between the mean ratings for each group was .77 $(p<.01)$. 
(a)

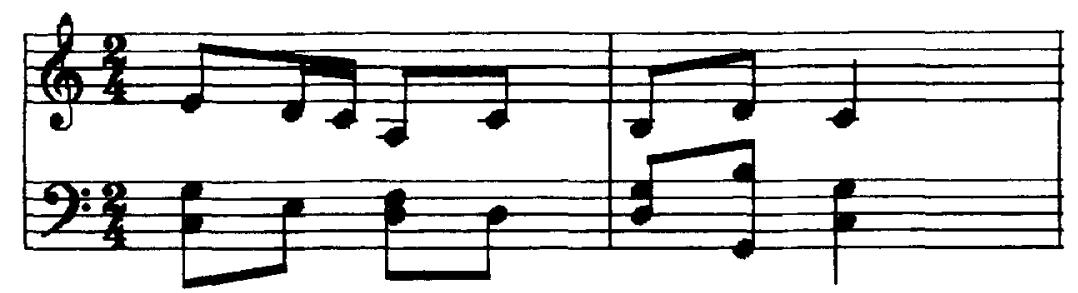

(b)

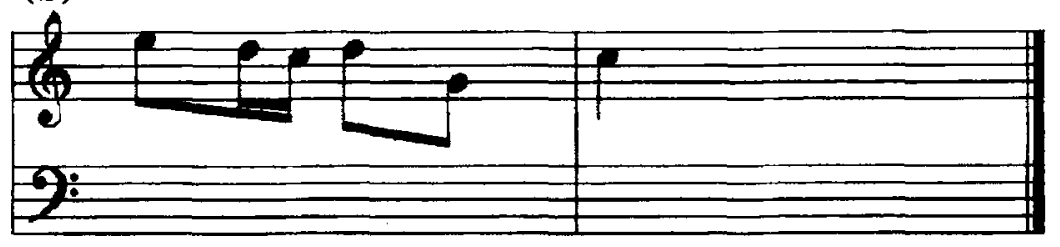

Figure 2. Musical passages used to establish the key of $\mathrm{C}$ major in the familiarization part of the experiment (a) and in the test part (b).

\section{Effect of Tonal Harmonic Hierarchies}

A musical training (2) $\times$ chord (50) analysis of variance (ANOVA) was performed with chord as the withinsubjects variable. Three planned comparisons were run to assess the effect of tonality on perceived musical tension. The first one contrasted the 12 diatonic chords with the 38 nondiatonic ones. The tension ratings for diatonic chords were significantly lower than those for nondiatonic chords $[F(1,26)=126.89, p<.001]$. The effect of key membership was significantly more pronounced for the musicians $[F(1,26)=4.52, p<.05]$. A second planned comparison was run to contrast the ratings observed for the more important diatonic chords (i.e., C, F, and G chords) with those observed for the less important ones (i.e., $d, e, a, b^{\circ}$ chords). There was a significant effect of the structural importance of chords $[F(1,26)=21.29, p<.001]$, with musical tension lower for the more important chords. This effect was stronger for musicians $[F(1,26)=12.81$, $p<.01]$. The third planned comparison contrasted the ratings observed for the tonic chord with those observed for the subdominant and dominant chords. Tonic chords received lower ratings of tension $[F(1,26)=20.66, p<.001]$. The interaction with musical training was not significant.

The averaged ratings obtained for the 24 major and minor triads were then correlated with the harmonic hierarchy values reported by Krumhansl (1990, Table 7.3). There was a significant negative correlation for the musicians and for the nonmusicians (Table 4).

In order to assess the link between the tonal hierarchies and perceived musical tension, the ratings for the seven diatonic triads were compared with Krumhansl's within-key values. There was a significant negative correlation for the musicians but not for the nonmusicians (Table 4). The nonmusicians' ratings differed from Krumhansl's withinkey values mainly because of the high tension ratings assigned to the dominant $(\mathrm{G})$ and subdominant chords $(\mathrm{F})$. The ratings observed for several triad subgroups were also compared with Krumhansl's (1990) harmonic hierarchy values. With the musicians, the only discrepancy observed was for the nine nondiatonic major triads (Table 4). Taken together, the present findings are generally consistent with the harmonic hierarchy values reported by Krumhansl (1990) (Figure 3). This provides some evidence that there is a negative relation between musical tension and tonal hierarchy: structurally more important chords tend to produce the lowest feeling of musical tension.

The tension ratings were then compared with the tonal pitch space distances (Table 5). Significant correlations were observed over all the 50 chords and for all of the chord subgroups considered in the analysis. Generally, pitch space distances tended to be more strongly correlated with the musicians' ratings. These findings suggest that tonal pitch space distance provides a good fit for perceived tension, especially for the musicians: the greater the distance in pitch space, the higher the perceived musical tension (Figure 4).

\section{Effect of Chord Mode and Chord Type}

The effects of chord mode (major vs. minor) and chord type (triads vs. seventh chords) were addressed through a $2 \times 2 \times 2 \times 12$ mixed factorial design. The two levels of musical training defined the between-subjects variables;

Table 4

Correlations Between the Present Tension Ratings and Krumhansl's (1990) Harmonic Hierarchy Values

\begin{tabular}{lcc}
\hline & & \multicolumn{1}{c}{$r$} \\
\cline { 2 - 3 } & Musicians & Nonmusicians \\
\hline 24 triads & $-.64 \dagger$ & $-.43^{*}$ \\
7 diatonic triads & $-.86^{*}$ & -.65 \\
12 major triads & $-.87 \dagger$ & $-.76 \dagger$ \\
12 minor triads & $-.84 \dagger$ & $-.64^{*}$ \\
18 nondiatonic chords & $-.47^{*}$ & -.19 \\
9 nondiatonic minor triads & $-.92 \dagger$ & $-.77^{*}$ \\
9 nondiatonic major triads & -.13 & -.26 \\
\hline
\end{tabular}



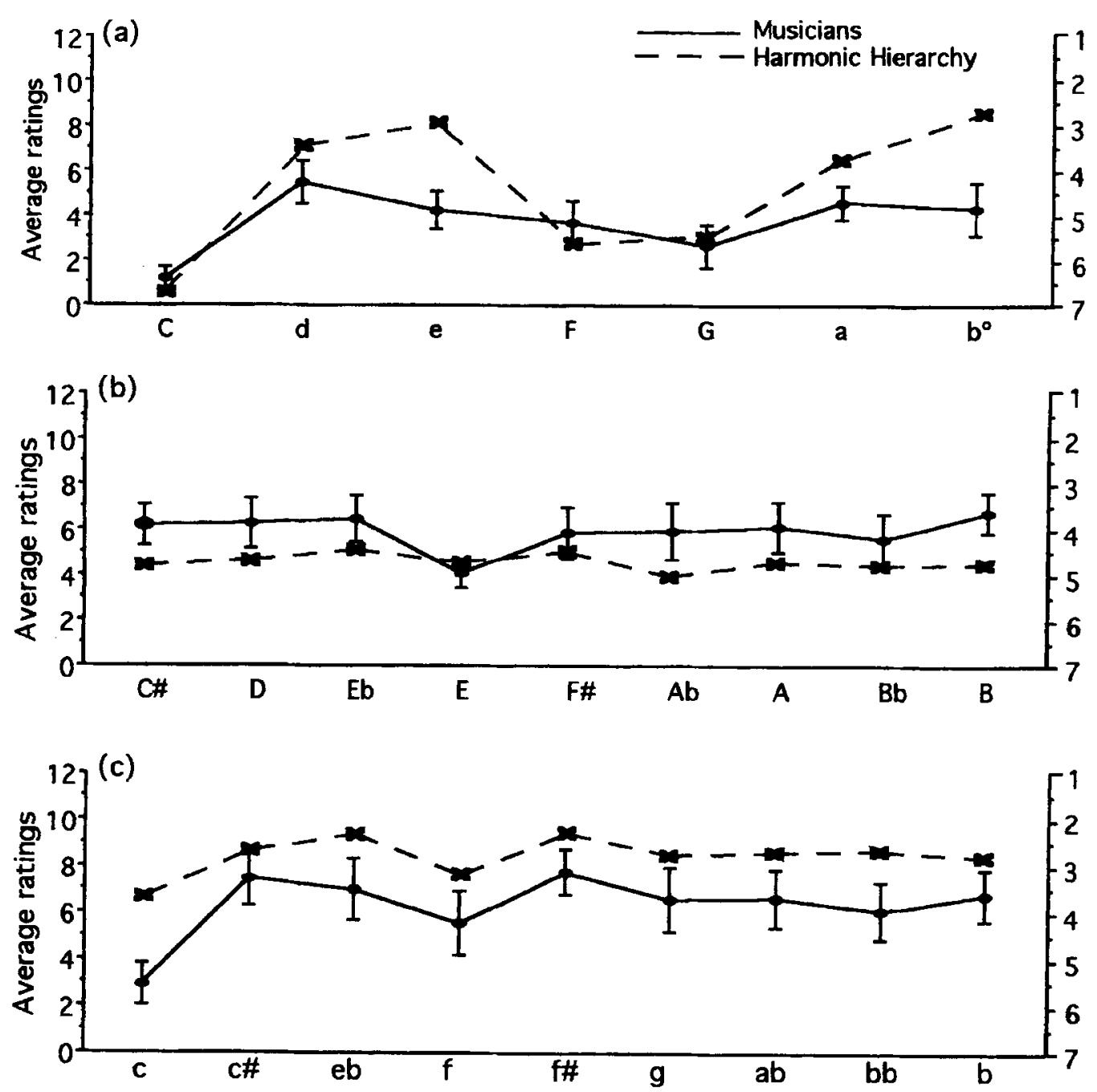

Figure 3. Comparison of the musical tension data (left scale) with Krumhansl's (1990) harmonic hierarchy data (right scale). The $95 \%$ confidence intervals of mean responses of the musicians (vertical bars) are shown for (a) the diatonic triads, (b) the nondiatonic major triads, (c) the nondiatonic minor triads.

the two levels of chord mode and chord type and the 12 levels of roots ( 12 chromatic scale degrees) defined the within-subjects variables. The ANOVA revealed a highly significant effect of chord mode $[F(1,26)=53.78, p<.001]$, with musical tension higher for minor chords, and a highly significant effect of chord type $[F(1,26)=46.18, p<.001]$, with musical tension higher for seventh chords. There were also significant interactions between musical training and chord mode $[F(1,26)=4.65, p<.05]$, and between musical training and chord type $[F(1,26)=12.18, p<.002]$; both effects tended to be more pronounced for the musicians. The interaction between chord mode and roots was also significant $[F(11,286)=14.60, p<.001]$ with the major/minor effect inverted or null on scale degrees ii (D minor), iii (E minor), and vi (A minor) (Figure 5). This was not surprising, given that diatonic chords on these scale degrees have minor thirds in major keys. No first- order interaction was observed between the chord mode and chord type, but the second-order interaction of chord mode, chord type, and roots was significant $[F(11,286)=$ $3.10, p<.001]$ : adding a seventh to a triad differently affected the musical tension, depending on both its root and mode. For example, adding a seventh to the $F \#$ triad provoked an increase in tension when the triad was major and a decrease in tension when it was minor. Conversely, adding a seventh to the $\mathrm{E} b$ triad provoked a decrease in tension when the triad was major, and an increase when it was minor.

The rest of the analysis assessed how these effects of chord mode and chord type might be accounted for by psychoacoustical models of sensory dissonance. The tension ratings of chords were correlated with the roughness values (Table 5). There was a weak but significant correlation only for the musicians: the higher the roughness, the 
Table 5

Correlations Between the Present Tension Ratings and the Tonal Pitch Space Distances, the Roughness Values and the Pitch Commonality Values

\begin{tabular}{|c|c|c|c|c|c|c|}
\hline & \multicolumn{2}{|c|}{$\begin{array}{c}\text { Tonal Pitch Space } \\
\text { Distances }\end{array}$} & \multicolumn{2}{|c|}{$\begin{array}{l}\text { Roughness } \\
\text { Values }\end{array}$} & \multicolumn{2}{|c|}{$\begin{array}{c}\text { Pitch Commonality } \\
\text { Values }\end{array}$} \\
\hline & Musicians & Nonmusicians & Musicians & Nonmusicians & Musicians & Nonmusicians \\
\hline 50 chords & $.77 \dagger$ & $.62 \doteqdot$ & $.37^{*}$ & .10 & $-.66 \dagger$ & $-.63 t$ \\
\hline 24 triads & $.83 \dagger$ & $.73 \dagger$ & .10 & -.19 & $-.81 \dagger$ & $-.86 \dagger$ \\
\hline 7 diatonic triads & $.94 \dagger$ & $.88^{\dagger}$ & .44 & .08 & $-.79^{*}$ & $-.82^{*}$ \\
\hline 18 nondiatonic triads & $.63 \dagger$ & $.59 \dagger$ & -.25 & -.44 & $-.69 \dagger$ & $-.81 \dagger$ \\
\hline 24 triads plus seventh & $.66+$ & $.55 \dagger$ & .22 & .35 & $-.46^{*}$ & $-.46^{*}$ \\
\hline 24 major chords & $.75 \dagger$ & $.68+$ & $.43^{*}$ & .15 & $-.66 \dagger$ & $-.75 \dagger$ \\
\hline 24 minor chords & $.71+$ & $.60 \dagger$ & .16 & .00 & $-.68 \dagger$ & $-.62 \dagger$ \\
\hline
\end{tabular}

higher the perceived tension. Considering different chord subgroups revealed a significant correlation only with the 24 major chords for the musicians.

The tension ratings were then correlated with the pitch commonality values (Table 5). For both groups there were significant negative correlations, indicating that the higher the pitch commonality, the lower the perceived tension. In addition, the pitch commonality values matched much better with the 24 triad ratings than with the 24 seventh chord ratings (triads plus seventh). The correlation coefficients observed for the 24 major chords were similar to those observed for the 24 minor chords, and the pitch commonality values correlated significantly with the seven diatonic triads and with the 18 nondiatonic triads.

\section{Effect of Horizontal Motion}

The last effect investigated concerned the influence of horizontal motion. A planned comparison was run, contrasting the ratings obtained for Trial la with those obtained for Trial 1e (Figure 1). Trial le created higher ratings of tension $[F(1,26)=89.34, p<.001]$, and the effect of horizontal motion was much larger for the nonmusicians $[F(1,26)=37.50, p<.001]$. The tonal importance of the $C$ chord probably tempered the effect of horizontal motion for the musicians.

To assess how the ratings observed for all the chords can be accounted for by the horizontal motion model, a multiple regression analysis was performed, predicting the data from the total size of the melodic intervals between the two chords in the soprano, alto, tenor, and bass voices. A linear model provided a moderate fit for the musicians' data $[R=.62, F(4,45)=6.94, p<.001]$ and a good fit for the nonmusicians' data $[R=.87, F(4,45)=33.85, p<$ $.001]$. For both groups the soprano and the bass values contributed most strongly to the regression model (Table 6). Surprisingly, the soprano was one of the voices with the least horizontal movement. One possible explanation of such a finding is that the small amount of horizontal motion created by the soprano is counterbalanced by its strong perceptual salience. The perceptual salience of the higher, outer voice has also been reported in other experimental studies (Francès, 1958; Palmer \& Holleran, 1994; Thompson \& Cuddy, 1989; Zenatti, 1981).

\section{Combination of the Different Models}

As we have seen, the harmonic hierarchy values (Krumhansl, 1990), the tonal pitch space distances (Lerdahl, 1988), the pitch commonality values (Parncutt, 1989), and the horizontal motion values all provided a good fit for perceived tension. The roughness values (Hutchinson \& Knopoff, 1978) also provided a significant fit for the musicians' ratings. Therefore it was of interest to assess how these theoretical models act when combined. In order to minimize the number of predictors entering into the multiple regression analyses, the four horizontal motion values were averaged without weighting and were regrouped in a unique variable labeled "mean values for horizontal motion."

The five variables were first correlated with each other (Table 7). Not surprisingly, the harmonic hierarchy values correlated significantly with the tonal pitch space distances, since the latter provide a formal and explanatory account for the former. Surprisingly, the pitch commonality values correlated significantly with the mean values for horizontal motion: the larger the interval traversed by each voice, the smaller the number of common perceived pitches. There was also a high correlation between the tonal pitch space distances and the pitch commonality values. Both Lerdahl's (1988) and Parncutt's (1989) models, despite their different theoretical foundation, predict in a similar way the strength of harmonic relationships between successive chords - a finding to which we will return later.

Because of the theoretical link between Krumhansl's (1990) harmonic hierarchy values and Lerdahl's (1988) tonal pitch space distances, two separate regression analyses were performed. A first multiple regression analysis was performed to predict the tension ratings registered for the triads from the harmonic hierarchy values, the pitch commonality values, the roughness values, the mean values for horizontal motion, and the extent of musical training. Musical training was coded as a dummy variable (Cohen \& Cohen, 1983). A linear combination of these five variables provided a good fit for the data $[R=.85$, $F(5,46)=24.70, p<.001]$. There was a significant contribution of the harmonic hierarchy values $(t=2.12, p<.05)$, of the pitch commonality values $(t=4.73, p<.01)$, of the mean values for horizontal motion $(t=2.52, p<.01)$, and of musical training $(t=3.76, p<.01)$. There was also a 

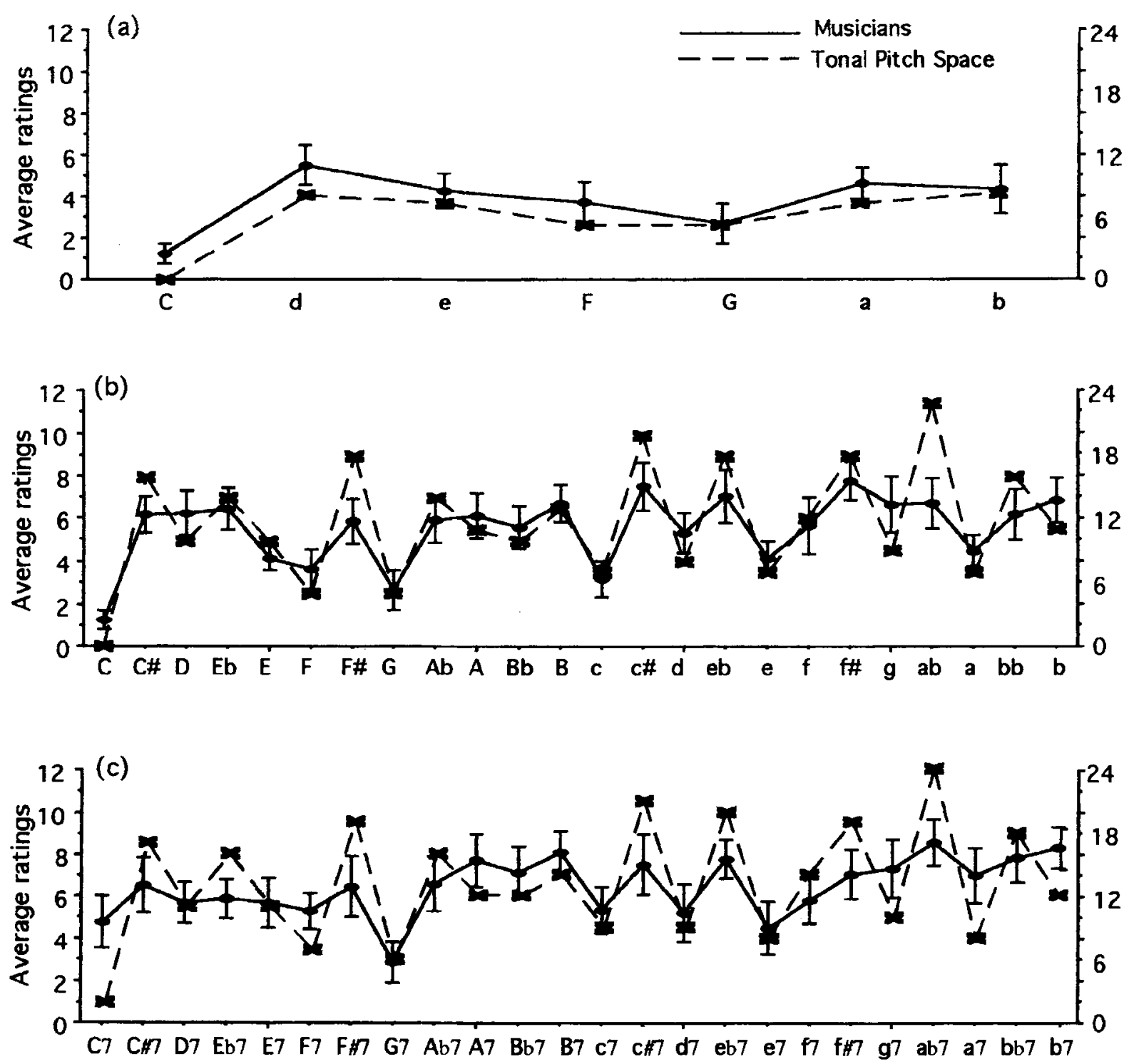

Figure 4. Comparison of the musical tension data (left scale) with Lerdahl's tonal pitch space distances (right scale). The $95 \%$ confidence intervals of mean responses of the musicians (vertical bars) are shown for (a) the diatonic triads, (b) the major and minor triads, (c) the dominant and minor seventh chords.

significant interaction between the mean values for horizontal motion and musical training $(t=2.52, p<.02)$, indicating that horizontal motion contributed differently for the musicians and for the nonmusicians. Semipartial correlations, computed for each group separately, revealed that the pitch commonality values and the harmonic hierarchy values made significant unique contributions to perceived tension for the musicians, while the mean values for horizontal motion and the pitch commonality values made direct contributions to tension for the nonmusicians (Table 8).

A second multiple regression analysis was performed to predict the tension ratings registered for the 50 chords from the tonal pitch space distances, the pitch commonal- ity values, the roughness values, the mean values for horizontal motion, and the extent of musical training. A linear combination of these five variables provided a good fit for the data $[R=.84, F(5,94)=46.29, p<.001]$. The tonal pitch space distances contributed significantly to the model $(t=6.25, p<.001)$, as did the mean values for horizontal motion $(t=7.42, p<.001)$ and musical training $(t=3.29$, $p<.001)$. There were also significant interactions between the roughness values and musical training $(t=2.49$, $p<.02$ ), and between the mean values for horizontal motion and musical training $(t=4.09, p<.001)$. Regression analyses were therefore performed separately, and the semipartial correlations were computed for each group of listeners (Table 9). 


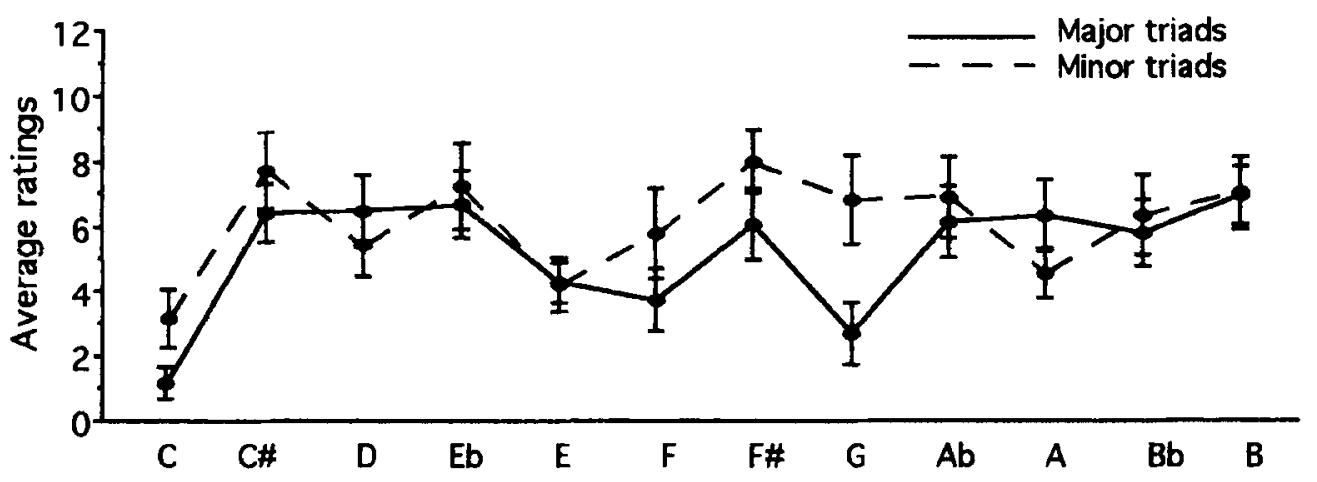

Figure 5. Effect of chord mode on tension for the musicians.

For both groups, the tonal pitch space distances and the mean values for horizontal motion both made significant unique contributions to tension. The former variable was the most important one for the musicians, the latter for the nonmusicians. The roughness values contributed directly to tension for the musicians only. The pitch commonality values had a significant direct relationship to tension only when the tonal pitch space distances values were not taken into account or, for the nonmusicians, when the mean values for horizontal motion were excluded from the analysis. This suggests that the pitch commonality values were active over the 50 chords because they captured some of the same aspects as did the tonal pitch space distances and,

Table 6

Results of Multiple Regression Analysis Predicting the Data by a Combination of the Horizontal Values of the Four Voices

\begin{tabular}{llll}
\hline \multicolumn{1}{c}{ Subjects } & sr & $t$ & $p$ \\
\hline Musicians & & & \\
$\quad$ Soprano & .48 & 4.10 & $<.01$ \\
Alto & .19 & 1.62 & $>.10$ \\
Tenor & .08 & .71 & $\mathrm{n} . \mathrm{s}$. \\
$\quad$ Bass & .29 & 2.44 & $<.02$ \\
Nonmusicians & & & \\
$\quad$ Soprano & .52 & 6.98 & $<.01$ \\
Alto & .13 & 1.80 & $<.10$ \\
Tenor & .16 & 2.16 & $<.05$ \\
Bass & .28 & 3.80 & $<.01$ \\
\hline
\end{tabular}

Note-Musicians, $R=.62, F(4,45)=6.94, p<.001$; nonmusicians, $R=.87, F(4,45)=33.85, p<.001$, sr, semipartial correlation.

Table 7

Correlations Between the Harmonic Hierarchy Values, the Tonal Pitch Space Distances, the Pitch Commonality Values, the Mean Values for Horizontal Motion, and the Roughness Values

\begin{tabular}{lcccc}
\hline & $\begin{array}{l}\text { Harmonic } \\
\text { Hierarchy } \\
(N=26)\end{array}$ & $\begin{array}{c}\text { Pitch Space } \\
(N=50)\end{array}$ & $\begin{array}{c}\text { Pitch } \\
(N=50)\end{array}$ & $\begin{array}{c}\text { Horizontal } \\
\text { Motion }\end{array}$ \\
& $(N=50)$ \\
\hline Tonal pitch space & $-.60^{*}$ & & & \\
Pitch commonality & $.52^{*}$ & $-.75^{*}$ & & \\
Horizontal motion & -.22 & .26 & $-.45^{*}$ & \\
Roughness & $-.51^{*}$ & .23 & -.10 & .10 \\
\hline
\end{tabular}

${ }^{*} p<.01$. to a lesser extent, as did the mean values for horizontal motion.

Further analysis revealed that some variables contributed differently to musical tension, depending on the chord types considered (triads vs. seventh chords). There were significant interactions between chord type and pitch commonality $(t=3.20, p<.001)$ and between the chord type and the mean values for horizontal motion $(t=2.12, p<.05)$. Regression analysis performed separately for triads and seventh chords indicated that the pitch commonality values made a significant unique contribution to tension for the triads only $(\mathrm{sr}=.23, t=3.18, p<.01)$. The mean values for horizontal motion contributed more for the seventh chords $(\mathrm{sr}=.58, t=7.08, p<.01)$ than for the triads ( $\mathrm{sr}=.27, t=3.79, p<.01)$. There was no further evidence for any significant second-order interaction or for an interaction between chord mode (major/minor) and any other variable.

The rest of the analysis was devoted to understanding why Lerdahl's (1988) cognitive model and Parncutt's (1989) psychoacoustic model produced highly correlated predictions. Recall that three values are necessary to define the tonal pitch space distances. According to Lerdahl's (1988) notation, the $k$ value represents the number of changes in pitch class proximity; the $j$ value, the number of steps between two chords on the diatonic fifths circle; and the $i$ value, the number of steps between two regions on the chromatic fifths circle. The goal of the analysis was to understand which part of Lerdahl's formula may be responsible for the high correlation with the pitch commonality values. Multiple regression analysis revealed that a linear combination of the $i, j, k$ values accounted for $59 \%$ of the variation in pitch commonality values $[R=.77$, $F(3,46)=23.31]$. Only the $k$ values contributed significantly to the model $(t=4.91, p<.001)$. They directly explained $21 \%$ of the variation in pitch commonality values $(s r=.46)$. This suggests that the high correlation between the tonal pitch space distances and the pitch commonality values may be explained because the number of common perceptual pitches between two chords was correlated with the number of changes in pitch class proximity provoked by the second chord: the smaller the number of com- 
Table 8

Results of Multiple Regression for Each Group of Participants Predicting the Data From a Combination of the Harmonic Hierarchy Values, the Pitch Commonality Values, the Roughness Values, and the Horizontal Motion Mean Values

\begin{tabular}{llll}
\hline \multicolumn{1}{c}{ Subjects } & sr & $t$ & $p$ \\
\hline Musicians & & & \\
Harmonic hierarchy & .24 & 2.20 & $<.05$ \\
Pitch commonality & .44 & 3.95 & $<.01$ \\
Roughness & .05 & $<1$ & \\
$\quad$ Horizontal motion & .00 & $<1$ & \\
Nonmusicians & & & \\
$\quad$ Harmonic hierarchy & .11 & 1.13 & $>.10$ \\
Pitch commonality & .32 & 3.21 & $<.01$ \\
Roughness & .17 & 1.69 & $>.10$ \\
Horizontal motion & .38 & 3.80 & $<.01$ \\
\hline
\end{tabular}

Note-Musicians, $R=.86, F(4,21)=14.81, p<.001$; nonmusicians, $R=.89, F(4,21)=19.48, p<.001 . \mathrm{sr}$, semipartial correlation

Table 9

Results of a Multiple Regression for Each Group of Participants Predicting the Data for the 50 Chords From a Combination of the Tonal Pitch Space Distances, the Pitch Commonality Values, the Roughness Values, and the Horizontal Motion Mean Values

\begin{tabular}{|c|c|c|c|}
\hline Subjects & $\mathrm{sr}$ & $t$ & $p$ \\
\hline \multicolumn{4}{|l|}{ Musicians } \\
\hline Tonal pitch space & .39 & 4.83 & $<.01$ \\
\hline Pitch commonality & .03 & $<1$ & \\
\hline Roughness & .19 & 2.43 & $<.02$ \\
\hline Horizontal motion & .22 & 2.79 & $<.01$ \\
\hline \multicolumn{4}{|l|}{ Pitch commonality } \\
\hline without tonal pitch space & .48 & 4.97 & $<.01$ \\
\hline \multicolumn{4}{|l|}{ Pitch commonality } \\
\hline without horizontal motion & .14 & 1.66 & .10 \\
\hline \multicolumn{4}{|l|}{ Nonmusicians } \\
\hline Tonal pitch space & .30 & 4.83 & $<.01$ \\
\hline Pitch commonality & .03 & $<1$ & \\
\hline Roughness & .07 & $<1$ & \\
\hline Horizontal motion & .60 & 8.98 & $<.01$ \\
\hline \multicolumn{4}{|l|}{ Pitch commonality } \\
\hline without tonal pitch space & .31 & 3.94 & $<.01$ \\
\hline \multicolumn{4}{|l|}{ Pitch commonality } \\
\hline Witiout nornzontal motion & .31 & 2.21 & -.03 \\
\hline
\end{tabular}

Note-Musicians, $R=.84, F(4,45)=27.76, p<.001$; nonmusicians, $R=.90, F(4,45)=45.89, p<.01 . \mathrm{sr}$, semipartial correlation.

mon pitches, the greater the number of changes in pitch class proximity.

\section{DISCUSSION}

Musical tension is a central concept for most music analyses: for several authors, the structure of a western musical piece is partly determined by the way in which tensions and relaxations are displayed through time (Lerdahl \& Jackendoff, 1983; Meyer, 1956; Schenker, 1935). Therefore, perceiving the tensions that exist among the musical events may be one of the important features of musical understanding. The purpose of the present study was to investigate some of the factors that govern musical tension in short chord sequences, played with realistic piano-like sounds. As a main outcome, it appears that judgments of tension arose from a convergence of several cognitive and psychoacoustic influences, whose relative importance vary, depending on musical training.

The importance of harmonic hierarchies was supported by the three following facts. First, chords belonging to the key context created less tension than did nondiatonic chords. Second, diatonic chords falling on the first, fourth, and fifth scale degrees created less tension than did the other diatonic chords. Third, the musical tension experienced on the tonic chord was weaker than that experienced on the dominant and subdominant chords.

The importance of harmonic hierarchies was also supported by the significant, negative correlations observed between the present tension ratings and the perceived harmonic stability values reported by Krumhansl (1990). It should be noted that Krumhansl's studies differed from the present one in two main respects. First, her experimental task was to rate how well a chord fit with a preceding key-defining context (goodness of fit), whereas the present task was to evaluate the degree of musical tension created by the second chord. The global consistency observed between her findings and the present ones confirmed the negative relation between perceived harmonic stability and musical tension. The most important chords in the harmonic hierarchy created weaker musical tension for listeners. Such a negative relation is consistent with other results obtained by Bigand (1993b), with melodies. In addition, to require participants to evaluate either the goodness (or badness) of fit, or the musical tension created by one chord, may be considered as two strongly related ways to measure the same thing: a chord may fit badly in a context because it instills a strong musical tension, or vice versa. At least with such short chord sequences, musical tension and goodness (or badness) of fit may be considered as two sides of the same coin.

The second main difference between the present experiment and Krumhansl's is that her musical tones were built with five octave-spaced sine wave components (Shepard tones). The global consistency observed between her findings and the present data suggests that perceived hierarchies of harmonic stability are not limited to chords of Shepard tones and may be extended to piano-like sounds.

Lerdahl's (1988) theory appeared to provide a good theoretical account of the influence that tonal hierarchies have on perceived musical tension: the greater the distance in pitch space, the greater the perceived tension. The present data agree with recent data obtained by Kwak (1994), with Shepard tones. As an idealization, it is assumed that listeners have a mental representation of the tonal hierarchies, compatible with the structure of Lerdahl's tonal pitch space. During listening, a cognitive process possibly assigns to the chords a specific place in pitch space and computes the distances separating them from the tonic chord in the space.

Besides tonal hierarchies, perceptual features also influenced perceived musical tension. Three kinds of perceptual features have been distinguished. The first is linked to the sensory dissonance of chords (Mathews et al., 1987; Roberts \& Shaw, 1984). As a main tendency, minor chords 
and seventh chords were globally rated as inducing higher tension than were major chords and triads, respectively. These effects of chord mode and chord type were more pronounced with the musician listeners and were moderately, but significantly, accounted for by Hutchinson and Knopoff's (1978) model of roughness. The second perceptual feature, related to the perceived musical tension, concerns the number of common pitches between the successive chords. For both groups, Parncutt's (1989) pitch commonality values provided a good fit for the data, notably when subjects were considering the triads. This suggests that the number of perceived pitches common to successive chords might be one factor that governs musical tension: the weaker the pitch commonality values, the greater the perceived tension. The third perceptual feature concerns horizontal motion. Tension ratings increased when the interval traversed by each voice was systematically increased: the larger the melodic interval in each voice, the greater the perceived tension. The high percentage of variance directly accounted for by the horizontal motion, in most of the previous analyses, emphasized the importance that the melodic arrangements between successive chords had, for musical tension. This effect of horizontal motion may be related to the principle of melodic anchoring, defined by Bharucha (1984). The smaller the pitch distance between an unstable event and a stable one, the better the resolution of the tension created by the unstable event. In addition, that the effect of horizontal motion was more pronounced for nonmusicians is consistent with other findings reported by Parncutt (1989). In such experiments, musicians are generally less sensitive to melodic effects and are more sensitive to harmonic effects than nonmusicians. In summary, all these results provided evidence that sensory-driven processes are involved in the perception of musical tension.

The last question addressed in the present study concerns the way in which tonal hierarchies and perceptual factors act together to predict musical tension. One of the main issues of the study was to assess the extent to which cognitive models of tonal hierarchies can account for perceived musical tension. This question was crucial, because we might possibly consider the cognitive theory of tonal hierarchies as a by-product, or an over-theorization, of more elementary psychoacoustical phenomena such as roughness, pitch commonality, or melodic arrangement between chords. The present data nevertheless provided evidence that both Krumhansl's (1990) harmonic hierarchy values and Lerdahl's (1988) tonal pitch space distances made unique significant contributions to tension, when all these psychoacoustical features were taken into account. This suggests that musical tension perceived in short chord sequences cannot be explained by sensory driven processes alone. This finding is consistent with previous research of Bharucha and Stoeckig $(1986,1987)$.

Lerdahl's (1988) cognitive theory, Hutchinson and Knopoff's (1978) model of roughness, and the mean values for horizontal motion appeared to provide quite distinct and complementary theoretical accounts of musical tension. This was shown by the fact that these models contributed differently, depending on the extent of musical training. Nonmusicians appeared to have based their responses on the most easily perceivable features (i.e., melodic arrangement between the tones of successive chords). Musicians probably had greater knowledge of the tonal hierarchies and greater sensitivity to roughness, developed through musical tuition and practice. This interaction with musical training suggests that each of these three models refers to linked, but distinct, processes.

When these three models were taken into account in the multiple regression analysis, the pitch commonality values failed to contribute significantly to tension over the 50 chords. Two reasons were invoked: first, the pitch commonality values provided only a moderate fit for the 50 chords (notably for the seventh chords). Second, the part of the pitch commonality values that was moderately active over the 50 chords appeared to capture similar aspects, such as the tonal pitch space distances. The high correlation between the pitch commonality values and the tonal pitch space distances was further investigated. With such experimental stimuli, this correlation may be explained, because the number of pitches common to successive chords and the number of changes created in pitch class proximity by successive chords appeared to be two different measures of strongly related features of the chord sequences. On the one hand, that both models partially rely on related features is not surprising. Lerdahl's (1988) theory attempts to model cognitive structures of modern listeners, while Parncutt's (1989) theory attempts to describe the underlying psychoacoustic relationships that helped bring about the historical development of the cognitive structures. On the other hand, because the former theory emphasizes the tonal function of the chords, while the latter emphasizes their psychoacoustical features, we could have expected both of them to make (even small) direct contributions to perceived tension. In fact, the only piece of experimental support for such an assumption appeared when we considered the 24 major and minor triads. With these more consonant chords, Parncutt's model captured some specific aspects of musical tension not accounted for by the tonal pitch distances, the roughness values, and the horizontal motion.

\section{CONCLUSION}

The relationship between theoretical accounts of tonal hierarchies and psychoacoustical accounts of chordal dissonance has been a matter of discussion in both music theory and the psychology of music. The present study provides evidence that Lerdahl's (1988) cognitive theory, the Hutchinson and Knopoff (1978) model of roughness, and the model for horizontal motion defined in the present paper provide complementary accounts of musical tension and may refer to distinct cognitive processes. Nonmusicians were more influenced by the melodic arrangement between the chords; the musicians, by both the harmonic function of the chords and their specific roughness. The discussion pointed out the interdependency between Lerdahl's tonal pitch space and Parncutt's pitch commonality 
values. If the pitch commonality values should capture specific aspects of musical tension not accounted for by the tonal pitch space theory, this is more true for the more consonant triads. One way to investigate the interdependency of these two models further could be to test their predictions with longer chord sequences. It may be assumed that longer sequences will emphasize the differences between the tonal function of the chords and their psychoacoustical features. Accordingly, Lerdahl's and Parncutt's predictions should provide different direct contributions to perceived tension. In addition, the present findings appear to be globally consistent with the main conclusions drawn from musical expectancies studies. As reported by Carlsen (1981), Bharucha and Stoeckig (1986, 1987), Palmer and Krumhansl (1987a, 1987b), Boltz (1989a, 1989b), Schmuckler (1989), Abe and Oshino (1990), and Schmuckler and Boltz (1994), the musical event that best fits the expectancies created by a previous musical fragment tends to be one that is the most important in the tonal hierarchy of the key context and that provides the best melodic continuation of the fragment. This suggests that musical tension and musical expectancies may be globally governed by similar factors, notably by those related to the tonal hierarchies and horizontal motion.

\section{REFERENCES}

AвE, J., \& Oshino, E. (1990). Schema driven properties in melody cognition: Experiments on final tone extrapolation by music experts. Psychomusicology, 9, 161-172.

ANSERMET, E. (1961). Les fondements de la musique dans la conscience humaine [The foundations of music in human consciousness]. Nelchâtel: Delachaux et Niestlé.

Aures, W. (1985). Ein Berechnungsverfahren der Rauhigkeit [A model for calculating roughness]. Acustica, 58, 268-281.

Bharucha, J. J. (1984). Anchoring effects in music: The resolution of dissonance. Cognitive Psychology, 16, 485-518.

BharUCHA, J. J., \& KRUMHANSL, C. L. (1983). The representation of harmonic structure in music: Hierarchies of stability as a function of context. Cognition, 13, 63-102.

BhARUCHA, J. J., \& STOECKIG, K. (1986). Reaction time and musical expectancy. Journal of Experimental Psychology: Human Perception \& Performance, 12, 403-410.

Bharucha, J. J., \& Stoeckig, K. (1987). Priming of chords: Spreading activation or overlapping frequency spectra? Perception \& Psychophysics, 41, 519-524

BIGAND, E. (1990). Abstraction of two forms of underlying structure in a tonal melody. Psychology of Music, 18, 45-60.

Bigand, E. (1993a). Contribution of music to research on human auditory cognition. In S. McAdams \& E. Bigand (Eds.), Thinking in sound: The cognitive psychology of human audition (pp. 187-218). Oxford: Oxford University Press, Clarendon Press.

Bigand, E. (1993b). The influence of implicit harmony, rhythm and musical training on the abstraction of "tension-relaxation schemas" in tonal musical phrases. Contemporary Music Review, 9, 123-137.

Bitsch, M. (1957). Précis d harmonie tonale [Handbook of tonal harmony]. Paris: Alphonse Leduc.

BoLtz, M. G. (1989a). Perceiving the end: Effects of tonal relationships on melodic completion. Journal of Experimental Psychology: Human Perception \& Performance, 15, 749-761.

BoLt2, M. [G.] (1989b), Rhythm and "good endings": Effects of temporal structure on tonality judgments. Perception \& Psychophysics, 46, 9-17.

Boltz, M. G. (1993). The generation of temporal and melodic expectancies during musical listening. Perception \& Psychophysics, 53, $585-600$.
Boltz, M. G., \& Jones, M. R. ( 1986). Does rule recursion make easier to reproduce? If not, what does? Cognitive Psychology, 18, 389-431.

Bregman, A. S. (1990). Auditory scene analysis. Cambridge, MA: MIT Press.

Carlsen, J. C. (1981). Some factors which influence melodic expectancy. Psychomusicology, 1, 12-29.

CHAILley, J. (1951). Traité historique d'analyse musicale [A historical treatise of music analysis]. Paris: Leduc.

Clarke, E. (1989). Issues in language and music. Contemporary Music Review, 4, 9-23.

COHEN, J., \& COHEN, P. (1983). Applied multiple regression/correlation: Analysis for the behavioral sciences. London: Erlbaum.

COSTERE, E. (1954). Lois et styles des harmonies musicales [Rules and styles of musical hamonies]. Paris: PUE.

DowLING, W. J. (1978). Scale and contour: Two components of a theory of memory for melodies. Psychological Review, 85, 341-354.

Dowling, W. J., \& HaRwood, D. (1986). Music cognition. New York: Academic Press

Dowling, W. I., \& Hollombe, A. W. (1977). The perception of melodies distorted by splitting into several octaves: Effects of increasing proximity and melodic contour. Perception \& Psychophysics, 21, 60-64.

FranCÈs, R. (1958) La perception de la musique. Paris: Vrin. [Trans. by W. J. Dowling (1988). The perception of music. Hillsdale, NJ: Erlbaum.] Helmholtz, H. L. F. von (1877). Die Lehre von den Tonempfindungen als physiologische Grundlage für die Theorie der Musik (4th ed.). [Trans. by A. J. Ellis (1885). On the sensations of tone as a physiological basis for the theory of music. London: Longmans, Green. Reprint: New York: Dover.]

HutCHINSON, W., \& KNOPOFF, L. (1978). The acoustical component of western consonance. Interface, 7, 1-29.

IMBERTY, M. (1979). Entendre la musique: Sémantique psychologique de la musique [Listening to music: The psychological semantics of music]. Paris: Dunod.

JONES, M. R. (1987). Dynamic pattern structures in music: Recent theory and research. Perception \& Psychophysics, 41, 621-634.

JoNes, M. R., BolTZ, M. [G.], \& KIDD, G. (1982). Controlled attending as a funcion of melodic and temporal context. Perception \& Psychophysics, 32, 211-218.

JONES, M. R., BotTZ, M. G., \& KLEIN, J. M. (1993). Expected endings and judged duration. Memory \& Cognition, 21, 646-665.

Kameoka, A., \& Kurryagawa, M. (1969). Consonance theory, part II: Consonance of complex tones and its calculation method. Journal of the Acoustical Society of America, 45, 1451-1459.

Koechlin, C. (1930). Traité de l'harmonie [A treatise of harmony] Paris: Max Eschig

KRUMHANSL, C. L. (1979). The psychological representation of musical pitch in a tonal context. Cognitive Psychology, 11, 346-374.

KrumhansL, C. L. (1990). Cognitive foundations of musical pitch. New York: Oxford University Press.

Krumhansl, C. L., Bharucha, J., \& Kessler, E. J. (1982). Perceived harmonic structure of chords in three related musical keys. Journal of Experimental Psychology: Human Perception \& Performance, 8, 24-36.

KrumhansL, C. L., \& Kessler, E. J. (1982). Tracing the dynamic changes in perceived tonal organisation in a spacial representation of musical keys. Psychological Review, 89, 334-368.

KWAK, S. (1994). Mental representation of nonmusicians and musicians for pitches, chords, and musical keys. Unpublished doctoral dissertation, University of Texas, Dallas.

Lerdahl, F. (1988). Tonal pitch space. Music Perception, 5, 315-345

Lerdahl, F. (1991). Pitch-space journeys in two Chopin Preludes. In M. R. Jones \& S. Holleran (Eds.), Cognitive bases of musical communication (pp. 171-191). Washington, DC: American Psychological Association.

LERDAFL, F., \& JACKENDOFF, R. (1983). A generative theory of toral music. Cambridge, MA: MIT Press.

LONGUET-HIGGINS, H. (1978). The perception of music. Interdisciplinary Science Review, 3, 148-156.

Mathews, M. V., Pierce, J. R., \& Roberts, L. A. (1987). Harmony and new scales. In J. Sundberg (Ed.), Harmony and tonality (pp. 59-84). Stockholm: Royal Swedish Academy of Music

MeYer, L. B. (1956). Emotion and meaning in music. Chicago: University of Chicago Press. 
MEYER, L. B. (1973). Explaining music: Essays and explorations. Chicago: University of Chicago Press.

MoOre, B. C. J., \& GlasberG, B. R. (1983). Suggested formulae for calculating auditory-filter bandwidths and excitation patterns. Journal of Acoustical Society of America, 74, 750-753.

Palmer, C., \& Holleran, S. (1994). Harmonic, melodic, and frequency height influences in the perception of multivoiced music. Perception \& Psychophysics, 56, 301-312.

Palmer, C., \& Krumhansl, C. L. (1987a). Independent temporal and pitch structures in determination of musical phrases. Journal of Experimental Psychology: Human Perception \& Performance, 13, 116-126.

Palmer, C., \& Krumhansl, C. L. (1987b). Pitch and temporal contributions to musical phrase perception: Effects of harmony, performance timing, and familiarity. Perception \& Psychophysics, 41, 505-518.

PARNCUTT, R. (1988). Revision of Terhardt's psychoacoustical model of the root(s) of a musical chord. Music Perception, 6, 65-94.

PARNCUTT, R. (1989). Harmony: A psychoacoustical approach. Berlin: Springer-Verlag.

PlomP, R., \& LEVELT, W. J. M. (1965). Tonal consonance and critical bandwidth. Journal of the Acoustical Society of America, 38, 548-560.

Rameau, J. P. (1722). Traité d'harmonie. [Trans. by P. Gosset (1971). Treatise of harmony. New York: Dover.]

Riemann, H. (1893). Vereinfachte Harmonierlehre. [Trans. by H. Bewerunge (1895). Harmony simplified. London: Augener.]

Roberts, L. A., \& Shaw, M. L. (1984). Perceived structure of triads. Music Perception, 2, 95-124.

SChENKER, H. (1935). Der freie Satz. Vienna: Universal Edition. [Trans. by E. Oster (1979). Free composition. New York: Longman.]

SCHMUCKLER, M. A. (1989). Expectation in music: Investigation of melodic and harmonic processes. Music Perception, 7, 109-150.

SCHMUCKLER, M. A. (1990). The performance of global expectations. Psychomusicology, 9, 122-147.
SCHMUCKLER, M. A., \& Boltz, M. G. (1994). Harmonic and rhythmic influences on musical expectancy. Perception \& Psychophysics, 56, 313-325.

ShePard, R. N. (1964). Circularity in judgments of relative pitch. Journal of the Acoustical Society of America, 36, 2346-2353.

SHEPARD, R. N. (1982). Structural representations of musical pitch. In D. Deutsch (Ed.), Psychology of music (pp. 343-390). New York: Academic Press.

TERHARDT, E. (1974a). On the perception of periodic sound fluctuations (roughness). Acustica, 30, 201-213.

TERHARDT, E. (1974b). Pitch, consonance, and harmony. Journal of the Acoustical Society of America, 55, 1061-1069.

Thompson, W. F., \& CUDDY, L. L. (1989). Sensitivity to key change in chorale sequences: A comparison of single voices and four-voice harmony. Music Perception, 7, 15 [-158.

UNYK, A. M., \& CARLSEN, J. C. (1987). The influence of expectancy on melodic perception. Psychomusicology, 7, 3-23.

Vos, J. (1986). Purity ratings of tempered fifths and major thirds. Music Perception, 3, 251-257.

ZENATTI, A. (1981). L'enfant et son environnement musical: Étude expérimentale des mécanismes psychologiques d'assimilation musicale [The child and its musical environment: An experimental study of the psychological processes involved in musical assimilation]. Issy les Moulineaux: EAP.

Zwicker, E., \& Terhardt, E. (1980). Analytical expressions for critical-band rate and critical bandwidth as a function of frequency. Journal of the Acoustical Society of America, 68, 1523-1525.

(Manuscript received January 24, 1994; revision accepted for publication June 29, 1995.) 